\title{
Determinants of Cord Care Practices among Mothers in Abakaliki, Ebonyi State, South East, Nigeria
}

\author{
U. V. Asiegbu ${ }^{*}$, O. G. Asiegbu' ${ }^{2}$ C. T. Ezeonu ${ }^{1}$, O. B. Ezeanosikes ${ }^{3}$ B. N. Onyire ${ }^{3}$ \\ ${ }^{1}$ Institute of Child Health, Department of Paediatrics, Federal Teaching Hospital, Abakaliki, Nigeria \\ ${ }^{2}$ Department of Obstetrics and Gynecology, Federal Teaching Hospital, Abakaliki, Nigeria \\ ${ }^{3}$ Department of Paediatrics, Federal Teaching Hospital, Abakaliki, Nigeria \\ Email: *uzomavivianasiegbu@gmail.com
}

How to cite this paper: Asiegbu, U.V., Asiegbu, O.G., Ezeonu, C.T., Ezeanosike, O.B. and Onyire, B.N. (2019) Determinants of Cord Care Practices among Mothers in Abakaliki, Ebonyi State, South East, Nigeria. Open Journal of Preventive Medicine, 9, 43-50.

https://doi.org/10.4236/ojpm.2019.95005

Received: April 23, 2019

Accepted: May 28, 2019

Published: May 31, 2019

Copyright $\odot 2019$ by author(s) and Scientific Research Publishing Inc. This work is licensed under the Creative Commons Attribution International License (CC BY 4.0).

http://creativecommons.org/licenses/by/4.0/

\section{(c) (i) Open Access}

\begin{abstract}
Introduction: Unhygienic cord-care practices are major public health concern because of the associated gross neonatal and infant morbidity and mortality. Various factors have been linked to these practices. This study aims to identify the determinants of cord care practices among mothers in Abakaliki, Ebonyi State, South East, Nigeria. Methods: A cross sectional questionnaire based study involving women attending antenatal clinics and those who brought their babies to the immunization clinics of Federal Teaching Hospital, Mile Four Hospital and Maternal/Child Primary Health Care Center, all in Abakaliki. Results: Two hundred and seventy three mothers participated in the study. The majority of the participants aged 26 to 35 years (60.07\%), had tertiary education $(49.45 \%)$ and were business women (38.46\%). Mothers who had secondary and tertiary education basically applied methylated spirit (p-value 0.0014) and chlorhexidine (p-value 0.0289) as a form cord care while those who had primary or no formal education cared for cord using hot water, Vaseline, close up tooth paste and local herbs. The mothers educational status, occupation and parity also determined the care given the umbilical cord after birth. Conclusion: Cord care practices are determined and influenced by several factors in Ebonyi State. Health education and awareness campaigns should be upheld and targeted among women of child bearing age found in women meetings, local markets and primary health care delivery centers especially in the rural setting.
\end{abstract}

\section{Keywords}

Determinants, Cord Care, Practices, Mothers, Abakaliki 


\section{Introduction}

The umbilical cord is a soft, flexible structure that connects the developing fetus to the mother through the placenta from the sixth week of pregnancy until birth [1]. It contains blood vessels through which oxygen and nutrients get to the fetus as well as a means of waste elimination from the fetus [1]. This function of umbilical cord becomes unnecessary at birth, when the baby is able to breathe, eat, and void by themselves from the bladder and bowel. It is then clamped and cut close to the baby's body, leaving an umbilical stump. It is a painless procedure since there are no nerve fibers in the cord. The stump gradually dries, shrivels and separates from the body, usually between 5 and 15 days after birth with colour change from a yellow-green to black as it dries out [1]. During this period, the umbilical cord should be kept clean and dry to avoid infection. Some orthodox health institutions advocate the use of alcohol; others advise keeping the cord clean and dry only [2]. These practices have changed over time. In developing countries where hygienic conditions are poor and infection rates are high, topical antiseptics such as chlorhexidine is recommended by World Health Organizations [3].

Local perceptions, cultural practices and beliefs, religious background and socioeconomic circumstances influence the trend and what is used for cord care, unfortunately, these are harmful and they include charcoal, baby powder, Vaseline, cooking oil, used motor oil, breast milk, cow dung, chicken faeces and dust [4] [5] [6] [7]. A newly cut umbilical cord can be a pathway for bacteria that can cause newborn umbilical infection, sepsis and death [8] [9] [10] [11].

A clear understanding of the determinants of cord care practices will be helpful in addressing high rates of neonatal deaths from these unhealthy cord care practices. Hence this study aims to identify the determinants of cord care practices among mothers in Abakaliki, Ebonyi State, South East, Nigeria.

\section{Methods}

A cross sectional based study was conducted from June to August 2016. The minimum sample size of 350 was calculated using the formula as cited by Araoye's [12]. These included parous but pregnant women attending antenatal clinics and women who brought their babies to the well-baby/immunization clinics of Federal Teaching Hospital, Mile Four Hospital and Maternal/Child Primary Health Care Center, all in Abakaliki.

An initial pilot study was done at the Primary Health Care center using a structured researcher administered questionnaire; necessary modifications were made before administration of the modified questionnaires to the participants. Information on subject's age, parity, educational status, and ethnic group were retrieved, also what constituted cord care for their infants and who influenced their choice of care were obtained from the administered questionnaire.

Ethical approval was sought for and obtained from the ethical committee Federal Teaching Hospital, Abakaliki, Ebonyi state. A written Informed consent was also signed by the participant after due explanation of the details of the 
study. Confidentiality was maintained and voluntary participation upheld.

\subsection{Inclusion Criteria}

- Parous but pregnant women attending antenatal clinics whose last delivery is less than two years.

- Women who brought their babies to the well-baby/immunization clinics of Federal Teaching Hospital, Mile Four Hospital and Maternal/Child Primary Health Care Center, all in Abakaliki.

\subsection{Exclusion Criteria}

- Parous but pregnant women attending antenatal clinics whose babies are more than two years.

The socioeconomic status of the families was classified in accordance with the method described by Olusanya et al. [13].

Data analysis was done using Epi Info 7. 1. 3. 10 of CDC Atlanta. Data was presented in Tables and Figures. Student t-test was used for comparison of arithmetic means, while Chi squared test was used for comparison of proportions. Probability value of less than 0.05 was considered statically significant.

\section{Results}

Three hundred and fifty questionnaires were distributed. Of these 273 were returned, giving a response rate of $78 \%$. Seventy seven of these respondents were excluded for incomplete data.

\section{Demographic Characteristics}

The distribution of subjects according to maternal age, maternal level of education, maternal occupation, place of residence, ethnic group, religion and parity is shown in Table 1.

The comparison between substances applied in relation to the age of the mother showed no statistically significant difference as seen in Table 2.

The relationship between substances applied when compared to the educational level of the mother was statistically significant for all except for cow dung $(\mathrm{p}=0.0000)$ and tooth paste $(\mathrm{p}=0.0768)$ as shown in Table 3 .

When substances applied was compared with mothers occupation, Vaseline application was observed to be more in business women (26.7\%), this was statistically significant $(\mathrm{p}=0.0378)$ as shown in Table 4 .

The relationship between substance applied and the mother parity was not statistically significant in all but hot water application $(p=0.0193)$ which was seen most in $\geq$ Para 5 mothers $(50 \%)$ and methylated spirit application ( $\mathrm{p}=$ 0.0202) and seen most in Para 2 - 4 (Table 5).

\section{Discussion}

The majority of mothers who participated in the study were aged 26 - 35 year. This age group used mainly antiseptics to care for the umbilical cord as opposed to 
Table 1. Sociodemographic data.

\begin{tabular}{|c|c|c|}
\hline AGE IN YEARS & FREQUENCY & PERCENT \\
\hline$<15$ & 4 & $1.47 \%$ \\
\hline $15-25$ & 81 & $29.67 \%$ \\
\hline $26-35$ & 164 & $60.07 \%$ \\
\hline$>45$ & 2 & $0.73 \%$ \\
\hline TOTAL & 273 & $100.00 \%$ \\
\hline EDUCATIONAL LEVEL & FREQUENCY & PERCENT \\
\hline None & 7 & $2.56 \%$ \\
\hline Primary & 34 & $12.45 \%$ \\
\hline Secondary & 97 & $35.53 \%$ \\
\hline Tertiary & 135 & $49.45 \%$ \\
\hline Total & 273 & $100.00 \%$ \\
\hline OCCUPATION & Frequency & Percent \\
\hline Business woman & 105 & $38.46 \%$ \\
\hline Civil servant & 96 & $35.16 \%$ \\
\hline House wife & 72 & $26.37 \%$ \\
\hline Total & 273 & $100.00 \%$ \\
\hline RESIDENCE & Frequency & Percent \\
\hline Rural & 74 & $27.11 \%$ \\
\hline Urban & 199 & $72.89 \%$ \\
\hline Total & 273 & $100.00 \%$ \\
\hline ETHNICGROUP & Frequency & Percent \\
\hline Hausa & 5 & $1.83 \%$ \\
\hline Ibo & 261 & $95.60 \%$ \\
\hline Yoruba & 6 & $2.20 \%$ \\
\hline Others & 1 & $0.37 \%$ \\
\hline RELIGION & Frequency & Percent \\
\hline Christian & 265 & $97.07 \%$ \\
\hline Muslim & 8 & $2.93 \%$ \\
\hline Total & 273 & $100.00 \%$ \\
\hline PARITY & Frequency & Percent \\
\hline Para 1 & 91 & $33.33 \%$ \\
\hline Para 2 - 4 & 150 & $54.95 \%$ \\
\hline Para 5 and above & 32 & $11.72 \%$ \\
\hline Total & 273 & $100.00 \%$ \\
\hline
\end{tabular}


Table 2. Relationship between substance applied and mothers age.

\begin{tabular}{|c|c|c|c|c|c|c|c|c|}
\hline \multirow{2}{*}{ Substance applied } & \multicolumn{6}{|c|}{ Age of mothers in years } & \multirow{2}{*}{$x^{2}$} & \multirow{2}{*}{ p-value } \\
\hline & $<15$ & $15-25$ & $26-35$ & $36-45$ & $>45$ & Total & & \\
\hline Dusting powder & $1(25.0 \%)$ & $1(1.2 \%)$ & $1(0.6 \%)$ & $0(0 \%)$ & $1(50.0 \%)$ & $4(1.5 \%)$ & 49.1666 & 0.0000 \\
\hline $\begin{array}{l}\text { Local herbs } \\
\text { (nchaonwu) }\end{array}$ & $0(0 \%)$ & $1(1.2 \%)$ & $2(1.2 \%)$ & $0(0 \%)$ & $0(0 \%)$ & $3(1.1 \%)$ & 0.3468 & 0.9866 \\
\hline Cow dung & $0(0 \%)$ & $0(0 \%)$ & $0(0 \%)$ & $0(0 \%)$ & $0(0 \%)$ & $0(0 \%)$ & 0.0000 & 1.0000 \\
\hline $\begin{array}{l}\text { Toothpaste } \\
\text { (close-up) }\end{array}$ & $1(25.0 \%)$ & $7(8.6 \%)$ & $6(3.66 \%)$ & $0(0 \%)$ & $0(0 \%)$ & $7(5.1 \%)$ & 7.3276 & 0.1196 \\
\hline Vaseline & $0(0 \%)$ & $18(22.2 \%)$ & $26(15.9 \%)$ & $8(36.4 \%)$ & $1(50.0 \%)$ & $53(19.4 \%)$ & 7.9365 & 0.0939 \\
\hline Hot water & $2(50.0 \%)$ & $27(33.3 \%)$ & $44(26.8 \%)$ & $6(27.27 \%)$ & $1(50.0 \%)$ & $80(29.30 \%)$ & 2.4039 & 0.6619 \\
\hline Methylated spirit & $4(100 \%)$ & $65(80.25 \%)$ & $136(82.9 \%)$ & $20(90.9 \%)$ & $1(50.0 \%)$ & $53(82.78 \%)$ & 3.7273 & 0.4442 \\
\hline Chlorhexidine & $0(0 \%)$ & $7(8.64 \%)$ & $30(18.29 \%)$ & $2(9.09 \%)$ & $1(14.29 \%)$ & $39(14.29 \%)$ & 5.7423 & 0.2192 \\
\hline
\end{tabular}

p-value $<0.05$ is statistically significant; $\chi^{2}<5$ is not a valid test.

Table 3. Relationship between substance applied and educational status.

\begin{tabular}{cccccccc}
\hline \multirow{2}{*}{ Substance applied } & \multicolumn{3}{c}{ Level of education } & \multirow{2}{*}{$\chi^{2}$} & p-value \\
\cline { 2 - 6 } & None & Primary & Secondary & Tertiary & Total & & \\
\hline Dusting powder & $1(14.3 \%)$ & $0(0 \%)$ & $2(2.1 \%)$ & $1(0.8 \%)$ & $4(1.5 \%)$ & 9.2049 & 0.0267 \\
Local herbs (nchaonwu) & $0(0 \%)$ & $2(5.9 \%)$ & $1(1.1 \%)$ & $0(0 \%)$ & $3(1.1 \%)$ & 8.7401 & 0.0330 \\
Cowdung & $0(0 \%)$ & $0(0 \%)$ & $0(0 \%)$ & $0(0 \%)$ & $0(0 \%)$ & 0.0000 & 1.0000 \\
Tooth paste (close-up) & $1(14.3 \%)$ & $4(11.8 \%)$ & $6(6.2 \%)$ & $3(2.2 \%)$ & $14(5.1 \%)$ & 6.8506 & 0.0768 \\
Vaseline & $2(28.6 \%)$ & $11(32.4 \%)$ & $24(24.7 \%)$ & $16(11.9 \%)$ & $53(19.4 \%)$ & 10.7084 & 0.0134 \\
Hot water & $4(57.1 \%)$ & $17(50.0 \%)$ & $34(35.1 \%)$ & $25(31.1 \%)$ & $80(29.3 \%)$ & 18.7754 & 0.0003 \\
Methylated spirit & $3(42.7 \%)$ & $23(67.7 \%)$ & $82(84.5 \%)$ & $118(87.4 \%)$ & $226(82.9 \%)$ & 15.5295 & 0.0014 \\
Chlorhexidine & $0(0 \%)$ & $1(2.9 \%)$ & $11(11.3 \%)$ & $27(20.0 \%)$ & $39(14.3 \%)$ & 9.0275 & 0.0289 \\
\hline
\end{tabular}

p-value $<0.05$ is statistically significant; $\chi^{2}<5$ is not a valid test.

Table 4. Relationship between substance applied and mothers occupation.

\begin{tabular}{cccccccc}
\hline \multirow{2}{*}{ Substance applied } & \multicolumn{5}{c}{ Mothers occupation } & \multirow{2}{*}{$\mathcal{2}^{2}$} & p-value \\
\cline { 2 - 5 } & Housewife & Business women & Civil servants & Total & & \\
\hline Dusting powder & $2(2.8 \%)$ & $2(1.9 \%)$ & $0(0 \%)$ & $4(1.5 \%)$ & 2.4272 & 0.2971 \\
Local herbs (nchaonwu) & $0(0 \%)$ & $3(2.9 \%)$ & $0(0 \%)$ & $3(1.1 \%)$ & 4.8533 & 0.0883 \\
Cowdung & $0(0 \%)$ & $0(0 \%)$ & $0(0 \%)$ & $0(0 \%)$ & 0.0000 & 1.0000 \\
Tooth paste (close-up) & $4(5.6 \%)$ & $8(7.6 \%)$ & $2(2.1 \%)$ & $14(5.1 \%)$ & 3.1954 & 0.2024 \\
Vaseline & $13(18.1 \%)$ & $28(26.7 \%)$ & $12(12.5 \%)$ & $53(19.4 \%)$ & 6.5485 & 0.0378 \\
Hot water & $25(34.7 \%)$ & $32(30.5 \%)$ & $23(24.0 \%)$ & $80(29.3 \%)$ & 2.4141 & 0.2991 \\
Methylated spirit & $54(75.0 \%)$ & $89(84.8 \%)$ & $83(86.5 \%)$ & $226(82.8 \%)$ & 4.2586 & 0.1189 \\
Chlorhexidine & $12(16.7 \%)$ & $11(10.5 \%)$ & $16(16.7 \%)$ & $39(14.3 \%)$ & 2.0222 & 0.3638 \\
\hline
\end{tabular}

p-value $<0.05$ is statistically significant; $\chi^{2}<5$ is not a valid test. 
Table 5. Relationship between substance applied and mothers parity.

\begin{tabular}{|c|c|c|c|c|c|c|}
\hline \multirow{2}{*}{ Substance applied } & \multicolumn{4}{|c|}{ Parity } & \multirow{2}{*}{$x^{2}$} & \multirow{2}{*}{ p-value } \\
\hline & Para 1 & Para 2 - 4 & $\geq$ Para 5 & Total & & \\
\hline $\begin{array}{l}\text { Dusting } \\
\text { powder }\end{array}$ & $2(2.2 \%)$ & $1(0.7 \%)$ & $1(3.1 \%)$ & $4(1.5 \%)$ & 1.6114 & 0.4468 \\
\hline $\begin{array}{l}\text { Local herbs } \\
\text { (nchaonwu) }\end{array}$ & $0(0 \%)$ & $2(1.3 \%)$ & $1(3.13 \%)$ & $3(1.1 \%)$ & 2.2956 & 0.3173 \\
\hline Cowdung & $0(0 \%)$ & $0(0 \%)$ & $0(0 \%)$ & $0(0 \%)$ & 0.0000 & 0.0000 \\
\hline $\begin{array}{l}\text { Tooth paste } \\
\text { (close-up) }\end{array}$ & $4(4.4 \%)$ & $7(4.7 \%)$ & $3(9.38 \%)$ & $14(5.1 \%)$ & 1.3523 & 0.5086 \\
\hline Vaseline & $14(15.4 \%)$ & $29(19.3 \%)$ & $10(31.25 \%)$ & $53(19.4 \%)$ & 3.8104 & 0.1488 \\
\hline Hot water & $22(24.2 \%)$ & $42(28.0 \%)$ & $16(50.0 \%)$ & $80(29.3 \%)$ & 7.8944 & 0.0193 \\
\hline $\begin{array}{l}\text { Methylated } \\
\text { spirit }\end{array}$ & $79(86.8 \%)$ & $126(84.0 \%)$ & $21(65.6 \%)$ & $226(82.8 \%)$ & 7.8030 & 0.0202 \\
\hline Chlorhexidine & $14(15.4 \%)$ & $22(14.7 \%)$ & $3(9.4 \%)$ & 39 (14.29\%) & 0.7377 & 0.6915 \\
\hline
\end{tabular}

p-value $<0.05$ is statistically significant; $\chi^{2}<5$ is not a valid test.

younger mothers who used toothpaste, Vaseline and hot water. Likely reasons might be lack of exposure, first timers or lack of female education. This is similar to a cross sectional survey in Kenya on the knowledge, attitude and practices of mothers and knowledge of health workers regarding care of the newborn umbilical cord by Obimbo, Musoke and Were [6] which also showed that poor knowledge, attitude and practice were associated with young, poor and low educated mothers. They recommended that health education on cord care be given at all levels of contact with mothers.

The educational level of mothers had a strong relationship with the umbilical cord status of their babies. Babies whose mothers had no formal education and those who attained primary level of education used harmful substances applications applied as umbilical cord care compared to those whose mothers had tertiary level of education. This has also been reported by Senarath, U., et al. [14] that higher level of education among mothers with new-born babies had a positive impact on clean cord care practice. Also, Abhulimhen-Iyoha and Ibadin [7] similarly found that the best predictors of beneficial cord practices are maternal level of education $(p=0.029)$.

The occupation of mothers was a strong determinant of cord care among the study group. Mothers who were civil servant cared for cords of their babies better than those who were housewives and business women.

It was observed that women who had just one baby (para 1) generally used methylated spirit and chlorhexidine more than mothers who have had many children. It is likely, that these women who have had many children may have support groups where they discuss and learn from their experiences necessitating their trial and use of other harmful substance with the hope of fast and early cord separation. 


\section{Limitation of the Study}

This study was hospital based. Findings may not reflect completely all varieties of cord care practices in the community. Hence, a community based study is recommended.

\section{Conflicts of Interest}

The authors declare no conflicts of interest regarding the publication of this paper.

\section{References}

[1] Zupan, J., Garner, P. and Omari, A.A. (2004) Topical Umbilical Cord Care at Birth. Cochrane Database of Systematic Reviews, 3, CD001057. https://doi.org/10.1002/14651858.CD001057.pub2

[2] Ireland, J., Rennie, A.M., Hundley, V., Fitzmaurice, A. and Graham, W. (2000) Cord-Care Practice in Scotland. Midwifery, 16, 237-245. https://doi.org/10.1054/midw.2000.0215

[3] World Health Organization (1998) Care of the Umbilical Cord: A Review of the Evidence. Maternal and Newborn Health/Safe Motherhood, Division of Reproductive Health (Technical Support), Family and Reproductive Health, World Health Organization, Geneva.

[4] Black, R.E., Cousens, S., Johnsons, H.L., Lawn, J.E., Rudan, I., Bassani, D.G., Jha, P., Campbell, H., Walker, C.F., Cibulskis, R., Eisele, T., Liu, L. and Mathers, C. (2010) Global Regional and Neonatal Causes of Child Mortality in 2008: A Systematic Analysis. Lancet, 375, 1969-1987. https://doi.org/10.1016/S0140-6736(10)60549-1

[5] Waiswa, P., Peterson, S., Tomson, G. and Pariyo, G.W. (2010) Poor Newborn Care Practices-A Population Based Survey in Eastern Uganda. BMC Pregnancy and Childbirth, 10, 9. https://doi.org/10.1186/1471-2393-10-9

[6] Obimbo, E. and Musoke, R.N. (1999) Were F KAP of Mothers and Knowledge of Health, Workers Regarding Care of the Newborn Umbilical Cord. East African Medical Journal, 76, 425-429.

[7] Abhulimhen-lyoha, B.I. and Ibadin, M.O. (2015) Cord Care Education and Content Given to Mothers at ANC in Various Health Facilities in Edo State, Nigeria. Sahel Medical Journal, 18, 129-133. https://doi.org/10.4103/1118-8561.169278

[8] Liu, L., Oza, S., Hogan, D., Perin, J., Rudan, I., Lawn, J.E., et al. (2015) Global, Regional, and National Causes of Child Mortality in 2000-13, with Projections to Inform Post-2015 Priorities: An Updated Systematic Analysis. Lancet, 385, 430-440. https://doi.org/10.1016/S0140-6736(14)61698-6

[9] Traverso, H.P., Bennett, J.V., Kahn, A.J., Agha, S.B., Rahim, H., Kamil, S. and Lang, M.H. (1989) Ghee Applications to the Umbilical Cord: A Risk Factor for Neonatal Tetanus. Lancet, 1, 486-488. https://doi.org/10.1016/S0140-6736(89)91378-0

[10] Mull, D.S., Anderson, J.W. and Mull, J.D. (1990) Cow Dung, Rock Salt, and Medical Innovation in the Hindu Kush of Pakistan: The Cultural Transformation of Neonatal Tetanus and Iodine Deficiency. Social Science \& Medicine, 30, 675-691. https://doi.org/10.1016/0277-9536(88)90253-5

[11] Karumbi, J., Mulaku, M., Aluvaala, J., English, M. and Opiyo, N. (2013) Topical Umbilical Cord Care for Prevention of Infection and Neonatal Mortality. Pediatric Infectious Disease Journal, 32, 78-83. 
https://doi.org/10.1097/INF.0b013e3182783dc3

[12] Araoye, M.O. (2003) Research Methodology with Statistics for Health and Social Sciences. Nathadex Publishers, Ilorin, 115-129.

[13] Olusanya, O., Okpere, E. and Ezimokhai, M. (1985) The Importance of Social Class in Voluntary Fertility Control in a Developing Country. West African Journal of Medicine, 4, 205-212.

[14] Senarath, U., et al. (2007) Factors Associated with Maternal Knowledge of Newborn Care among Hospital Delivered Mothers in Sri Lanka. Transactions of the Royal Society of Tropical Medicine and Hygiene, 101, 823-830.

https://doi.org/10.1016/j.trstmh.2007.03.003 